\title{
Pablo de Lora, Lo sexual es político (y jurídico*
}

\author{
(2019) Alianza Editorial
} Madrid, 347 pp.

\author{
Jesús Ignacio Delgado Rojas \\ Universidad Carlos III de Madrid \\ ORCID ID 0000-0002-3818-5990 \\ jesusignacio.delgado@uc3m.es
}

\section{Cita recomendada:}

Delgado Rojas, J. I. (2020). Pablo de Lora, Lo sexual es político (y jurídico). Eunomía. Revista en Cultura de la Legalidad, 18, pp. 430-436.

doi: https://doi.org/10.20318/eunomia.2020.5292

Me es grato recensionar el último libro del profesor Pablo De Lora. Y me es grato por las razones que paso a exponer. En primer lugar, aplaudo la oportunidad del momento de su aparición: el contexto global que hoy nos rodea justifica el que un filósofo del Derecho se haya ocupado -por fin- de este tema. La llamada «cuarta ola del feminismo», el movimiento \#MeToo, el sonado caso de La Manada en España o la reforma legislativa que requiere el delito de violación eran cuestiones que reclamaban una aproximación teórica desde la Filosofía del Derecho. Y Pablo De Lora no sólo se ha ocupado de estos temas, sino que lo ha hecho con rigor y, sobre todo, preocupado por la deriva que han tomado algunos de los análisis que se vienen elaborando desde el feminismo radical hegemónico o mainstream.

Pablo de Lora, profesor de Filosofía del Derecho de la Universidad Autónoma de Madrid, de un modo más zorro que erizo, aborda una serie de cuestiones que, situándose en las lindes o fronteras de nuestra disciplina iusfilosófica, nos resultan cuanto menos retadoras e inquietantes. Desde el primer párrafo de su Introducción, nos revela su declaración de intenciones en forma de interrogantes: "¿Quién debe lavar y zurcir los calcetines? ¿Debe estar prohibido masturbar a mi mascota? ¿Y que alguien practique una felación a un discapacitado físico severo a cambio de dinero?

\footnotetext{
* El 18 de diciembre de 2019 el profesor Pablo de Lora fue invitado a un seminario en la Universidad Pompeu Fabra para discutir sobre cuestiones estudiadas en este libro. No pudo realizar su ponencia al sufrir un boicot, con agravios e insultos, por parte de un grupo de activistas que impidió su intervención. Se sume esta recensión a todas las muestras de apoyo y solidaridad que recibió el profesor De Lora, reivindicando la libertad de expresión y la libertad académica.
} 
¿Por qué no pueden tener relaciones sexuales los hermanos si son mayores de edad y usan anticonceptivos? ¿Por qué se inscribe el sexo del recién nacido en el Registro Civil? ¿Debe permitirse la celebración de orgías? Y si la respuesta es sí: ¿por qué no puedo casarme con varios hombres o varias mujeres? ¿Y disponer de un robot-niño con el que disfrutar de mis fantasías pedófilas, o programarlo para simular una violación? ¿Se es o se llega a ser hombre? ¿Y qué consecuencias jurídicas debe tener si lo somos o llegamos a serlo? ¿Se habrá de terminar con la segregación por sexos en los baños públicos? ¿Y qué será del feminismo si el sexo-género es disponible?» (p. 13). Ningún filósofo del Derecho se había adueñado de esta batería de polémicas preguntas. Pablo de Lora se trae magistralmente estas cuestiones a nuestro terreno y las va contestando a lo largo de las 347 páginas de su libro.

El título de la obra es un claro guiño al viejo mantra del feminismo que en los setenta enunciara la feminista estadounidense, tildada de radical, Carol Hanisch ( $p$. 16). A lo que De Lora acertadamente añade entre paréntesis 'y jurídico'. Efectivamente, lo sexual es político, jurídico y también -añadiría ahora yo- 'filosófico'. Pues esta última perspectiva creo que es la que adopta, dada su filiación académica, el profesor De Lora al abordar estos temas. Y es el tratamiento que echábamos en falta en torno a estas cuestiones.

Aludo a lo acertado del título porque me parece que en él reside el eje central de la argumentación de De Lora. Desde la tradición liberal clásica iniciada con Stuart Mill que llega hasta nuestros días en la obra de John Rawls, se puede rastrear una indudable conexión entre lo público y lo político, de tal forma que ciertos contextos de la actividad humana, por contra, los relativos a la vida privada y familiar -por usar tanto la terminología de la Declaración Universal de Derechos Humanos (1948, art. 12) como la de la Convención Europea de los Derechos Humanos (1950, art. 8)-, permanecen ajenos a la intervención del poder público.

No es extraño que el liberalismo haya sido el abanderado de esta distinción y que sea lo propio de los totalitarismos de toda índole el esforzarse por difuminar tanto como sea posible los contornos del ámbito privado y penetrar en ellos con toda violencia. Pero reconozcamos: las fronteras no son tan nítidas. El poder público ni puede ni debe dejar de intervenir en el dominio de lo personal-privado, porque incluso cuando decide no hacer nada -evitando prohibir- ya está haciendo algo: valorando moralmente como mejor la abstención a la intervención. La cuestión no es, por lo tanto, la de si la vida sexual de los ciudadanos es una cuestión política o no -no puede dejar de serlo-, sino cómo puede serlo; la discusión relevante no es si el poder público debe o no interferir en el dominio de lo privado, sino la de cómo debe hacerlo y qué razones puede esgrimir válidamente para ello (p. 17).

Huelga decir que todo ordenamiento jurídico está inspirado en una filosofía política y en una serie de valores y principios morales (de moralidad pública y social, mayoritaria o no). De la misma manera, el ordenamiento jurídico puede ser objeto tanto de valoración jurídica como de evaluaciones morales y políticas. El Derecho, por tanto, no es neutral al incorporar una serie de valores e intereses desde el mismo momento en que se opta por el Estado de Derecho y no por otro modelo. Detrás del Derecho estatuido por ese Estado hay una concepción del mundo, hay unos valores y no otros y hay una apuesta por el papel central que ocupa en ese mundo el ser humano autónomo. Por ello, la pretendida neutralidad del Estado liberal no busca vaciar de moralidad el espacio público, sino más bien subrayar la importancia de un trato imparcial a todas las personas dado en pie de igualdad cuando adoptan decisiones que tienen que ver con sus proyectos de vida buena, de florecimiento humano o de excelencia personal. Y aquí es donde De Lora se sirve de compañeros de lujo para este peregrinaje: desde el conjunto de ideas que conforman la tradición 
liberal, con su reticencia a que el poder público intervenga en la vida privada de los individuos por razones perfeccionistas y el criterio del daño, hasta la primacía del individualismo y el universalismo morales. De la mano de tan nobles principios, De Lora nos intentará seducir con la idea de que la mejor tradición del feminismo es la liberal (p. 19). Estamos, pues, ante la recurrente cuestión filosófico-política del liberalismo político acerca de la separación o no de la esfera de lo público y lo privado. El viejo asunto de la neutralidad (más pretendida que real) del Estado liberal.

En cuanto al contenido del libro, distribuido en seis capítulos agrupados en dos partes de tres capítulos cada una, se reconduce a dos temas principalmente: el sexo y el género.

Por el lado del sexo, se aborda el tabú del incesto (p. 26), los problemas derivados del consentimiento en las relaciones sexuales (por ejemplo, el 'solo sí es sí), la fornicación, la robotfilia, la zoofilia o el bestialismo, la pedofilia, la prostitución, el sentido y formas del matrimonio (la poligamia, el matrimonio entre hermanos), y la gestación subrogada (p. 145). Cuestiones todas ellas que han despertado y siguen despertando en la conciencia de muchos individuos inquietudes, contrariedades 0 cuando no, directamente, una profunda repugnancia.

Por el lado de las cuestiones sobre el género, De Lora realiza valientes análisis sobre ultimísimas cuestiones planteadas por la división entre sexo y género (en especial, la transexualidad), el uso de baños públicos mixtos (p. 171), el discutido derecho a ser aludido por medio de un pronombre neutro (p. 173) y la libre disponibilidad del sexo o género (el derecho a no declararse varón ni hembra, sino no-binario). Cuestión esta última que De Lora encuentra incomprensible y que contraargumenta mediante reducción a un absurdo categorial, mostrando su imposibilidad lógica (p. 195). En un segundo grupo de cuestiones sobre el género, De Lora abre un amplio y articulado debate sobre los problemas jurídicos y políticos de la lucha contra la violencia de género, sus dificultades conceptuales ( $p .211$ ) o los riesgos que entraña la denominada "falacia de la frecuencia» como expediente justificatorio del endurecimiento de las condenas (p. 233). Y, finalmente, ofrece una valiosa reflexión conceptual sobre los estudios de género, aportándonos además su crítica sobre los excesos en los que estos análisis están incurriendo (p. 253).

El libro se cierra con un epílogo en el que De Lora nos invita a participar de la reconstrucción que realiza de la conversación imaginaria que podrían mantener Betty Friedan y Simone de Beauvoir cuarenta y cuatro años después de su encuentro parisino (con el que De Lora abría su libro). Si ambas mantuvieran hoy una conversación como la de 1975, a juicio de De Lora, no podrían más que conceder que todo feminismo -nunca radical- debe ser un humanismo, que apuntaría en el fondo a la «igualdad de todos los seres humanos, independientemente de su condición» ( $p$. 273).

Deseo resaltar tres ejes que vertebran el libro de De Lora. El primero sería una crítica al feminismo hegemónico, radical o mainstream. Para este feminismo radical toda relación heterosexual sería sospechosa de dominación dada la asimetría en las relaciones de poder entre hombres y mujeres. Por tanto, la apelación al consentimiento sería siempre tramposa y no cabe apelar a él para creer que una relación sexual no viciada sea posible. MacKinnon, su correligionaria A. Dworkin y, en el plano nacional, B. Gimeno o C.G. Magdaleno, serían ejemplos de posiciones perfeccionistas, pues estarían instando a las ciudadanas a seguir un modelo de vida virtuoso (sólo las relaciones sexuales consentidas dentro del matrimonio bajo el fin de la procreación no serían dominantes ni heteropatriarcales) y a rechazar toda relación heterosexual por encubrir una forma de dominación masculina en la que el coito es 
siempre una forma de violación que coloca a la mujer bajo la dependencia del varón y de la especie (p. 44, parafraseando a Beauvior).

Este feminismo actual tiende a hacer de la mujer un sujeto menor de edad, vulnerable, propenso a equivocarse, débil y, por tanto, digno de proteger (es el caso de las que propugnan el abolicionismo de la prostitución, ya que cualquier libre elección de las mujeres que intercambian sexo por dinero es falaz e ilusa, o de las que no conciben la subrogación por sustitución ni siquiera sin que medie precio...). Son posicionamientos que ponen en duda la autonomía personal de la mujer. ¿Dónde quedó el empoderamiento -se podría uno preguntar-cuando se le sustrae a la mujer su capacidad de decisión por la de una política perfeccionista que vela para que no se equivoque? Si el feminismo más radical piensa que la decisión de una trabajadora sexual siempre es errónea, ¿no se le está negando directamente a la mujer su capacidad para escoger libremente esa opción de vida? Si una mujer elige lo que una feminista mainstream nunca elegiría, simplemente le dirían que está equivocada, que no sabe lo que hace, que estaría actuando bajo el dominio del heteropatriarcado o que está, lisa y llanamente, cegada ante lo que verdaderamente quiere y le interesa. Sólo elegir lo que el feminismo hegemónico dice que es bueno elegir constituye el verdadero empoderamiento.

En el relato del feminismo hegemónico la prostitución masculina queda como la gran olvidada. Pero De Lora sí tiene a bien citar algunos estudios actuales de rigor sobre el tema (pp. 100-101). Aunque no sea equivalente en número a la prostitución femenina, el individualismo moral nos obligaría a no olvidarnos de un trato digno por igual a todo ser humano.

El segundo motivo que destacaría del libro es su rigor conceptual. El profesor De Lora nos lanza un arsenal de cuestiones «peliagudas» que seguro provocan el «sonrojo» del lector. ¿Qué se cataloga como sexo?, ¿es el deseo un estado mental?, ¿comete adulterio aquel emparejado que ve pornografía o el que piensa en otra persona mientras mantiene sexo con su pareja?, ¿es la masturbación una relación sexual? Preguntas así le hacen a De Lora recurrir a las teorías del consentimiento para poder contestarlas. Lo que Alan Wetheimer consideró como una suerte de «transformador normativo» y que para De Lora haría «justificable lo que, de otro modo, sería inadmisible» (p. 30). Las razones por las que las relaciones sexuales se llevan a término no están sometidas al escrutinio de ninguna otra autoridad más que la de quienes la llevan a cabo. Frente al obstáculo kantiano que denunciaba que toda relación sexual es la pura instrumentalización del otro, en el Estado liberal el consentimiento troca en algo justificable el hacer del otro $u$ otra mero medio. El consentimiento transforma la relación sexual, por más moralmente dudosa que pudiera ser, en jurídicamente lícita (p. 55).

Hablar de consentimiento nos lleva siempre a las dificultades sobre su forma de prestarlo. De Lora analiza, por un lado, si el consentimiento que hace jurídicamente lícita la relación sexual requiere manifestarse de alguna forma precisa y, por otro, si la particular reprochabilidad de la violación depende sólo de que no se haya otorgado tal consentimiento en la forma en que estimamos que se debiera dar. Sobre lo primero, De Lora sostendrá no sólo que la relación sexual consentida no exige una específica solemnidad verbal estandarizada, sino que someter una relación sexual a ese protocolo sería per se disvalioso. Con respecto a lo segundo, defenderá que aquellas relaciones sexuales donde el consentimiento ha estado viciado o fue obtenido fraudulentamente no deben ser consideradas agresiones sexuales en pie de igualdad con aquellas en las que se dan condiciones de "tortura». Aunque el consentimiento se haya obtenido fraudulentamente si no ha habido «tortura» o «violencia», por más moralmente reprochable que nos parezca la relación, ésta no 
debe ser penalmente castigada. Habrá que ver cuán «fraudulentamente» se ha conseguido el consentimiento: la insinuación, el flirteo, la proposición, la galantería y el coqueteo no pueden sino entenderse como formas de sutiles engaños que se encaminan a buscar el consentimiento. Pero de esas prácticas no se puede derivar que se haya producido un vicio del consentimiento tal que nos lleve a hablar de violación. Habrá, obviamente, límites en esas "artes del cortejo», y lo que se considera ofensivo parece que tiene más que ver con las reglas del trato social y los gestos culturales que con ilícitos jurídicos (p. 65).

Ello nos lleva a poner el acento del delito de agresión sexual, no en el vicio del consentimiento, sino en la específica forma de tortura que entraña esa violación. ¿Cómo reconstruir la prohibición de la violación, es decir, cómo entender la severidad del castigo y su justificación -lo que los penalistas llamarían el bien jurídico protegidode acuerdo a una concepción no significativa del sexo? Si el sexo no tiene un fin propio, ¿por qué penar la violación más severamente que dañar a otro un sentido como la vista o hacerle perder un órgano? Aquí De Lora pone ejemplos de este problema de proporcionalidad penal muy ilustrativos que nos llevan al pantanoso terreno del populismo punitivo.

De Lora expone la tesis de Brownmiller, según la cual, la violación no es un delito intrínsecamente de naturaleza sexual, sino de violencia y tortura. «Esto no va de sexo, va de violencia», dicho brevemente. Lo que De Lora va a sostener es que la única manera de apostar por la severidad del castigo de la agresión sexual es asumiendo que algunas relaciones sexuales sí son significativas, esto es, no son desacralizables.

Ya nos avisó David Sussman que la gravedad moral de la tortura tiene que ver con cómo esa tortura logra en la víctima su autorrepudio (p. 52). El autorrepudio sería el contrario al autorrespeto enunciado por John Rawls (p. 54) como el más importante de los bienes primarios. Por eso, cuando alguien es violado alberga un profundo desprecio de sí mismo y adquiere un hondo sentimiento de humillación. Le han arrebatado lo más importante que tenía: la conciencia de su propio valor, su autoestima. De ahí que la severidad del castigo tenga que ver con ese autorrespeto perdido: el juez, al agravar la pena de la violación podría estar preguntándose por cuánto puede minar a un individuo el verse sometido a una situación violenta.

Y ello nos lleva al tercer eje que quería resaltar de la obra de De Lora. ¿Cómo entender o cómo reconstruir la significación que en principio atribuimos a la relación sexual en un Estado liberal en el que ciertas prácticas institucionales, sociales y reglas persisten contrariando ese supuesto fin de la actividad sexual? (p. 36). Nos enfrentamos a una "concepción desacralizada del sexo» (que De Lora sitúa en los sesenta con la aparición de los anticonceptivos femeninos, p. 119) que supone la ruptura de la barrera entre la relación sexual por placer y por reproducción. A partir de esa desacralización, el fin de la relación no tiene por qué ser necesariamente el reproductivo. En cambio, nuestras instituciones y normas jurídicas siguen considerando "perversiones sexuales» ciertas relaciones que no comulgan precisamente con el fin marital y reproductivo del sexo saludable. Si el sexo puede basarse en el puro placer, el sexo protegido por el Derecho, en cambio, sigue siendo el propiamente familiar y reproductivo. No hay concordancia entre nuestra visión acerca del sexo y el Derecho de un Estado liberal acerca de la moralidad sexual.

Se preguntaba la que fuera diputada de Podemos en la Asamblea de Madrid Beatriz Gimeno, y actualmente directora del Instituto de la Mujer, si había una manera justa de follar (2018, Sexo y empatía. Las bases éticas del follar, Revista Contexto). A lo que ella misma contestaba: "Somos las mujeres las únicas que consentimos, 
mientras que ellos desean y actúan; nos follan. Nosotras, así, nos situamos como objeto deseado y pasivo, mientras que ellos son el sujeto activo que, con suerte, pide el consentimiento para el acceso a nuestro cuerpo».

Propuestas así le llevan a De Lora a plantearse si cabe hablar de justicia en las relaciones sexuales. Será injusta si no cumple su fin, esto es, que sea contra natura. Y aquí De Lora se opone a aceptar algunas tesis de Finnis y Scruton que nos harían comulgar con verdades reveladas acerca del sexo y del matrimonio que tienen más que ver con la religión y el tabú que con la razón. La relación será justa, en cambio, si cumple su fin, ya sea este el de la reproducción, el amor, el placer mutuo o la empatía -como diría Gimeno-. Parece que estas son buenas razones para mantener relaciones sexuales; esto es, dotan de un fin a la relación. Todas estas razones se reconducen, como vemos, a la idea de consentimiento: la moral sexual liberal tiene como eje normativo que haya consentimiento libre y voluntariamente prestado. Pero en lo que De Lora llama la visión desacralizada del sexo, ¿dónde encontrar este fin para saber si dicho fin se está cumpliendo, y poder catalogar la relación como justa? Teme De Lora que fruto de esa desacralización del sexo, en la que el sexo puede haber pasado a tener la misma relevancia moral que tantas otras funciones corporales y fisiológicas, no sea fácil atribuirle un sentido o fin a la práctica sexual. Perdido este fin, se podría uno preguntar por qué las instituciones siguen manteniendo la pornografía en la clandestinidad o persiste la condena del exhibicionismo, por ejemplo.

Acabo con cuatro conclusiones telegráficas que podemos extraer del libro de De Lora. Primero. La moralidad sexual liberal se asienta sobre una concepción significativa de la relación sexual, aunque quizás no extraordinariamente significativa ni muy densa. Pero la desacralización del sexo que se produce en la sociedad (el no tener que vernos obligados a darle un fin en sí mismo al coito) no encaja con otras muchas instituciones, reglas e incluso percepciones que seguimos manteniendo acerca del sexo. Segundo. El sexo que nos despoja de nuestra autoposesion corporal, es decir, la relación sexual llevada a cabo mediante una afrenta a nuestro propio cuerpo, mina las bases del autorrespeto. De ahí que pueda justificarse la severidad del castigo de la violación por encima de otros delitos que podrían parecernos que causan «males» mayores. Tercero. La autonomía moral es condición necesaria pero no suficiente para la licitud moral del sexo. Hay formas de engaño, fraude o error (que no entran en el juego de la seducción o que están más allá de las reglas del trato social) que constituyen ofensas a la moralidad sexual. Esos engaños vician el consentimiento. Si bien el engaño es un indicador de que pueda haber agresión sexual (ahí están las contrariedades del relato clásico del Rapto de Lucrecia o vean la película Boy's dont cry), no cabe considerar que toda seducción sea una forma de engaño. ¿Qué son el galanteo y el cortejo sino formas de engaño para despertar la atención del ser querido? (p. 73). Y cuarto. En una sociedad liberal, el asco, el disgusto o la repugnancia son malos consejeros para legislar (p. 94). Las fantasías ajenas, por mucho que nos disgusten, no pueden ser objeto de interferencia. Esa es la inviolabilidad, nos recuerda T. Nagel, de una esfera íntima y privada de la persona que informa un compromiso con los derechos humanos (p. 80). Es también el derecho a la independencia moral de los individuos del que nos hablaba R. Dworkin en Una cuestión de principios cuando defendía un derecho a no resultar desfavorecido en la distribución de bienes y oportunidades sociales, entre los cuales se cuentan las libertades que les garantiza el Derecho penal, solo porque sus funcionarios o conciudadanos piensan que sus opiniones sobre cuál es el modo correcto de vivir sus vidas son innobles o equivocadas. El gobierno violaría este derecho a la independencia moral cuando la justificación que utilizara para restringir la conducta sexual recurriera a los motivos de una mayoría de personas que les repugna que otros miembros de su comunidad (por cuyas vidas desperdiciadas o poco florecidas sienten 
aversión) se abocan a tales prácticas. Un Derecho penal de corte liberal, es decir, que utiliza el castigo para evitar conductas que dañan intereses o bienes jurídicos básicos, no puede justificar la tipificación de un comportamiento por ser este poco virtuoso, indecoroso o porque a algunos miembros de la comunidad les molesten las prácticas a las que otros se abandonan en privado (p. 94). El Derecho penal de un Estado liberal no está para hacernos virtuosos, sino para evitar el que otros nos impidan serlo.

Me permito realizar dos puntualizaciones últimas, una sobre el fondo y otra sobre la forma. Sobre el fondo, ensalzo la valentía de De Lora para entrar en enjundiosos debates, expuestos con profundidad argumentativa y rigor analítico. Admiro la serenidad con la que De Lora sale airoso de algunos charcos en los que se mete. Y lo hace de la mano de la mejor tradición del liberalismo político, la autonomía y el individualismo moral. No puedo más que estar de acuerdo con esa perspectiva. Sobre la forma, sólo haría notar que la opción de llevar las notas al final del libro, en vez de a pie de página, suele ser engorrosa. Hay muchas notas de interés para el lector común que contienen aclaraciones sustantivas y no sólo de mera referencia bibliográfica. Aunque sobre esto ya sabemos que donde hay patrón (editorial) no manda marinero...

Creo compartir la convicción feminista liberal a la que nos invita De Lora y la defensa por una igualdad de derechos entre hombres y mujeres, al modo básicamente universalista e individualista, que nos acerca a la mejor tradición del feminismo ilustrado (que va desde los escritos de Mary Wollstonecraft y Condorcet a Harriet Taylor y Stuart Mill). Este feminismo entiende que las diferencias entre hombres y mujeres son, en gran medida, aunque no por completo, una construcción social. Frente a ello, creo que las categorías hombre-mujer pueden volverse a convertir en identidades esencialistas en el discurso del feminismo radical (p. 165), quizás más por exceso verbal o falta de matización teórica que por expreso deseo. Flaco favor estarían haciendo Andrea Dworkin y Catharine MacKinnon a aquellas que precisamente dicen estar empoderando.

En el suplemento Babelia del diario El País (11/09/2019) se publicaba una entrevista con Margaret Atwood, en la que la autora de El cuento de la criada afirmaba que "de forma natural me sale ser una vieja zorra malvada», y añadía: «la verdad es que hay todo tipo de mujeres. No pretendamos que son un tipo de ángeles que vuelan entre las nubes. Tienen imperfecciones y fallos como el resto, ¿y por qué no deberían tener derecho a ello?».

Cuidado con los intentos de teorizar sobre cuestiones tan íntimas como el sexo o el género. Ese es el aviso de De Lora. No es que no haya límites ni concepciones significativas acerca de lo que es valioso en la vida. Sino que, como ya dijo el Comité Wolfenden acerca de la despenalización de la prostitución y la homosexualidad en Inglaterra a mediados del siglo XX, sencillamente no son asunto del Derecho. Porque precisamente lo que dota de valor a ese componente de la experiencia humana es que se encuentra vedado a la injerencia de la esfera pública. La moral, impuesta por la fuerza, deja de ser valiosa. La moral sexual igualmente no aguanta nada bien ese contagio con lo público o lo justo. Si lo sexual no puede dejar de ser político, «¿cuán político debe ser?» (p. 124). Seguramente el consentimiento libre e indudablemente prestado sea el mejor indicador para tomarnos en serio la autonomía personal. Las cuestiones referidas a la identidad sexual no pueden ser preestablecidas clínicamente de una vez y para siempre, como si pudiera inferirse algo así como una auténtica naturaleza humana sin incurrir en falacia fatal. Quizás no podamos dar un concepto de 'lo bueno', y tan sólo podamos conformarnos con dejar espacio para que cada uno lo busque a su manera, espontáneamente, con sus defectos y virtudes y con el trasfondo de eso que De Lora llama poéticamente «el ruido de la vida». 